\title{
Unilateral discectomy: outcomes, postoperative pain, complications
}

\author{
Fatemeh Mahboub Mojaz (1), Hesam Abdolhoseinpour (1), Reza Akhavan Sigari (2)
}

(1) Department of Neurosurgery, Bou Ali Hospital, Faculty of Medicine, Tehran Medical Sciences Branch, Islamic Azad University, Tehran, Iran; (2) Department of Neurosurgery, University Medical Center Tuebingen, Eberhard-Karls University, Tuebingen, Germany.

This article is distributed under the terms of the Creative Commons Attribution Noncommercial License (CC BY-NC 4.0) which permits any noncommercial use, distribution, and reproduction in any medium, provided the original author(s) and source are credited.

\begin{abstract}
In low back pain management surgery is currently commonly used with a new technique called minimally invasive discectomy, while open discectomy is still preferable in many cases. In this regard, the efficacy of tubular discectomy (TD) were compared with conventional standard lumbar disc procedure (conventional microdiscectomy). This study was performed as a clinical trial conducted on patients who were under TD and conventional microdiscectomy using unilateral retractor at Bou Ali, Mehrad, Laleh Hospitals during the years 2001 to 2017. The pain score was determined based on the use of Visual Analogue Scale (VAS). The Roland Morris Disability Questionnaires (RMQ) and mean Oswestry disability index (ODI) were also calculated. Our findings revealed that the two groups were similar in terms of demographic characteristics (age, sex, body mass index, etc.) ( $p>0.05)$. The findings indicated the superiority of TD over the classic approach. The mean scores of ODI in conventional microdiscectomy and TD groups were reported as $12.53 \pm 7.09$ and $9.51 \pm 7.83$, respectively. ODI revealed that patients with TD surgery had less disability in lifting objects, sitting, standing, and traveling. In the conventional microdiscectomy group, 12 (20\%) patients were affected by complications of surgery, but no complication was reported in any patient with TD $(p=0.000)$. The mean index of Roland Morris disability in the conventional microdiscectomy and TD groups were estimated to be $6.033 \pm 2.98$ and $3.73 \pm 3.25(\mathrm{p}=0.000)$. However, both groups did not differ in terms of visual scores for pain and relapse ( $p>0.05)$. Our study demonstrates that disease relapse within 6 months after the surgery, the RMQ and the ODI values were significantly better in TD than the other group.
\end{abstract}

Key Words: Open discectomy, oow invasive techniques, tubular discectomy, effectiveness.

Eur J Transl Myol 29 (3): 320-327, 2019

Back pain can be defined as the symptom of pain associated with dysfunction of one of the anatomical structures of the lower back, even if the pain is also felt in head or foot. ${ }^{1}$ According to several studies, low back pain is probably the most common cause of disability in patients under the age of 50 years and is the second most common cause of work-related visits to primary health services. In Iran, there are not many data on this subject. One study reported that $51 \%$ of Iranian peoples have experienced at least one chronic low back pain during their lifetime. According to the Ministry of Health of Iran, lower back pain imposes $7.5 \%$ of the burden of the disease on the health system of Iran. ${ }^{2-4}$

Epidemiologic studies have linked the abundance and severity of back pain with a number of personal factors, lifestyle, occupation, etc. They can be categorized into two modifiable and unmodified categories. Some examples of modifiable risk factors include weight, lifestyle and ergonomics at work, nutrition, exercise, mobility, and smoking. In contrast, some non-modifiable risk factors include genetic predisposition, bone anomalies, sex, and age. ${ }^{2,5,6}$. However, in people between 30 and 50 years of age, herniated disk is one of the relatively common cause of low back pain. One of the most important therapies in this regard is the use of discectomy. Discectomy is a surgical procedure to remove a herniated disk.

Discectomy is commonly used in the treatment of intervertebral disk herniation. The annual discectomy rate is reported at $80-60$ per 100,000 people and is the third most commonly occurring surgical procedure. The surgical procedure is generally recommended for patients with persistent pain. ${ }^{7-9}$ Open surgery has been introduced since the early twentieth century, where alternatives have 
been introduced. The purpose of introducing new approaches is to increase the effectiveness of treatment and decrease lesions during surgery. ${ }^{10-13}$ The treatment was modified by introducing primary microscopic laminectomy to microdiscectomy (MD). Various clinical studies have reported a high degree of success with this methodology. ${ }^{14}$ This method is usable in several types of herniated lumbar disc. The duration of action and overall complications will not increase, and will provide similar success rates to open discectomy approaches ${ }^{15}$ In recent years, the desire to use less invasive discectomy approaches has been growing; this has led to the introduction and development of various methods for spinal surgery. ${ }^{10,16}$ In the treatment of lumbar discs, less invasive approaches are preferred to open methods. ${ }^{17-19}$ In the year 1997, Caspar and Yasagil first introduced the microdiscectomy technique, which is based on at least an incision of the position toward open discectomy approaches. ${ }^{20-21}$ As previously mentioned, the purpose of these methods is to maximize the effectiveness of surgical techniques, which is the goal of all the less invasive approaches. Therefore, a microdoscopic discectomy technique was also introduced. ${ }^{22}$ In this technique, a $14 \mathrm{~mm}$ tubular retractor is used to create a surgical pathway to the lumbar spine. ${ }^{23} \mathrm{~A}$ tubular retractor along with the endoscope allows to visualize the position. Increasing the use of endoscopes in surgery has gradually revealed its limitations, including the limitations of vision and the creation of two-dimensional images. To overcome these problems, tubular retractor system was used along with the microscope. In general, using a microscope instead of using an endoscope led to the introduction of a micro TD technique. It seems that this method leads to similar or better results than conventional microdiscectomy and discectomy. However, other documents do not support this hypothesis. ${ }^{24-26}$. Thus, the aim of this study was to examine the efficacy of unilateral approach with microscope and tubular retractor system.

\section{Materials and Methods}

The present interventional study was conducted as a randomized clinical trial on patients who were under tubular discectomy (TD) or conventional standard lumbar disc procedure, that is conventional microdiscectomy([CMD) using unilateral retractor at Bou-Ali, Mehrad, Laleh (in Iran) and the University Hospital in Göttingen, Germany, during the years 2001 to 2017. Criteria for exclusion were: Multifaceted and non-symptomatic discs, no apparent instability, people with bilateral disks and patients with multiple traumas.

Patients' demographic information was entered in the data collection, and then the subjects were randomly assigned to one of two groups, either TD or CMD using a retractor. The pain score was next calculated based on VAS. Findings of the Roland Morris Disability Questionnaires (RMQ) and mean Oswestry disability index (ODI) were also determined. Then, the frequency
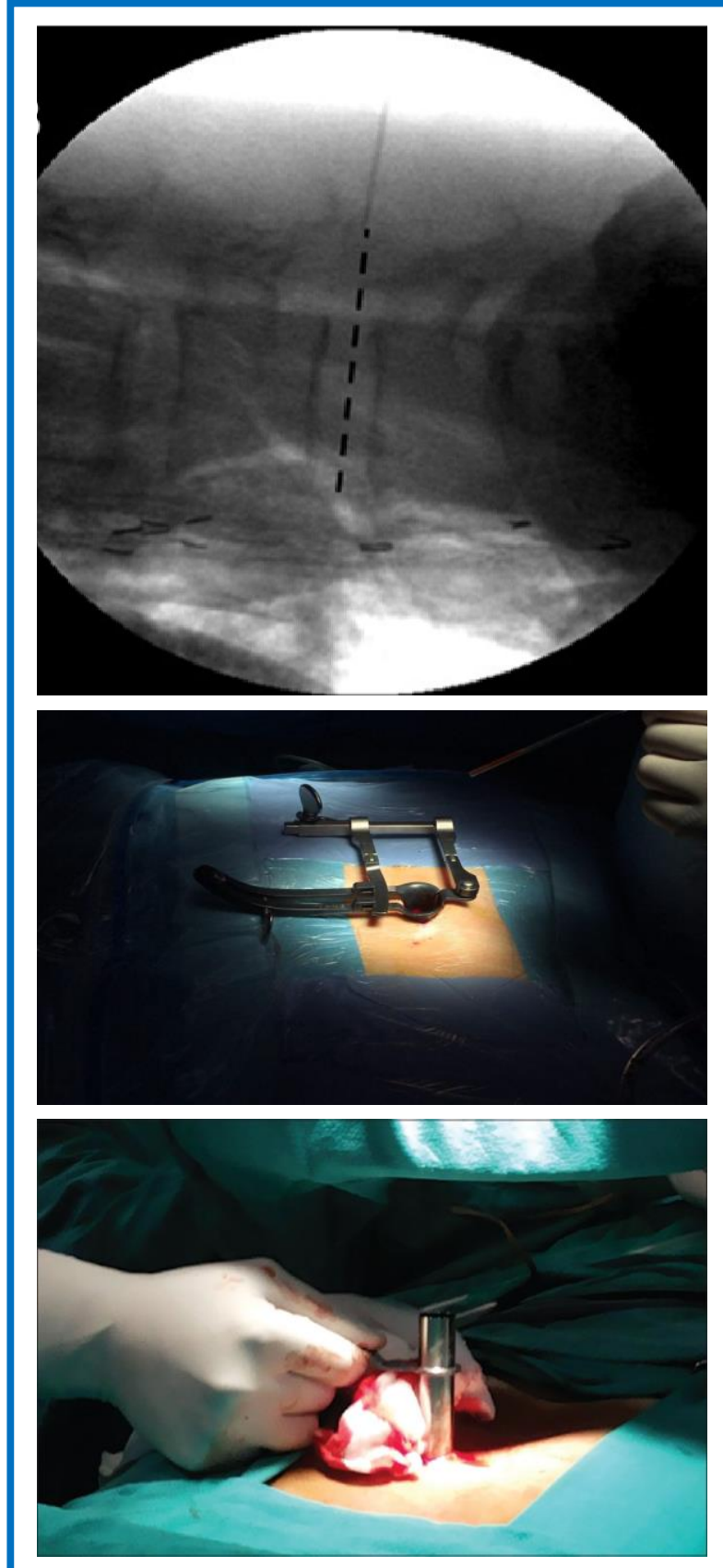

Fig 1. Tubular device at the surgical site

of complications was determined and compared at six months after operation. Data analysis was performed using SPSS software version 24. Moreover, the variables were evaluated by using the Kolmogorov-Smirnov, Mann-Whitney, and the Spearman's rank correlation coefficient test at a significant level less than 0.05. Using Kolmogrov-Smirnov test, the distribution of data related to quantitative variables was investigated. Since the distribution of data was abnormal, we applied Mann Whitney and Spearman to analyze correlations. In TD, surgery has been performed under general anesthesia and the patients were placed in a stable position. The Dilator 


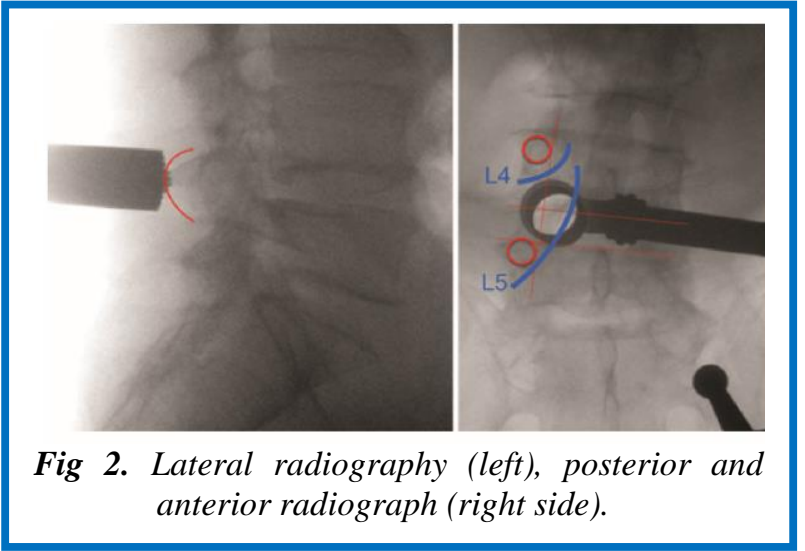

was directed through the intact tissue towards the affected area. Then dilator was located on the facet joints. The facet joints are in fact parts of the vertebrae that come close to each other. The facet joints move along the vertebral column. The movement of these fasts and the elasticity of the disc cause the vertebrae to move toward each other (Figure 1). Then a tubular retractor with a diameter of 20-16 mm was placed. The retractor always attaches to the facet joint, because this joint is a safe and proper point in the process of muscle relaxation. Anterior lateral and posterior radiography was then performed to ensure the optimal position of the working channel in the craniocodular axis (Figure 2). Final position before and during surgery is chosen through the careful examination of MRI. The microscope was also applied to visualize the position. The remaining fibers were burned and removed during operation; then a diamond drill was used to remove part of the bone. It should be noted that bone loss was minimized. All maneuvers that are performed in open microdisectomy can be performed via tubular retractor under a microscope. The movement of the retractor at different angles allows the surgeon to access the different parts of the spine. When the goals of the action were realized and enough homeostasis was

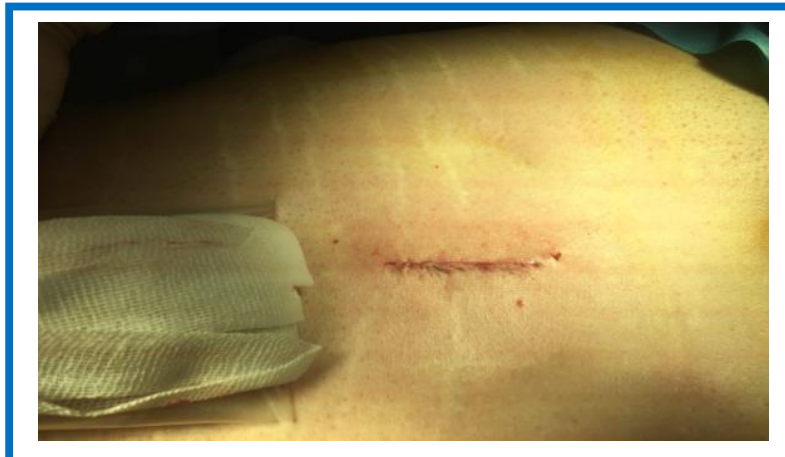

Fig 3. Surgical position after suturing.

provided within the spinal canal, the tube was extracted slowly and microbial detection was carried out in various layers of the paravertebral muscle and then cauterized. This is a precautionary and necessary measure to prevent hemorrhage. Finally, the $2 \mathrm{~cm}$ incision was closed through subcutaneous sutures (Figure 3).

\section{Results}

The two groups were similar in terms of demographic characteristics. Thus, the mean age of patients in the TD group was determined as $54 \pm 16.83$ years, while it was $55.89 \pm 15.56$ years in the CMD group. Twenty-eight patients $(46.7 \%)$ of the CMD group were women, while 37 patients $(60.7 \%)$ of TD group were belonged to women. Moreover, 9 patients (15\%) with CMDhad osteoporosis, while 15 patients with TD (24.6\%) suffered $59.27 \pm 7.53 \mathrm{~kg} / \mathrm{m}^{2}$, respectively. $68.1 \mathrm{~m} \pm 0.087,57.81$ $\pm 14.31 \mathrm{~kg}$, respectively. These variables in the other group were obtained to be as $82.27 \pm 4.38 \mathrm{~kg} / \mathrm{m}^{2}, 73.1$ $\pm 0.091 \mathrm{~m}$, and $83.46 \pm 14.43 \mathrm{~kg}$, respectively. In addition, $31(53.4 \%)$ of the patients in the CMD group and $27(44.3 \%)$ patients in the TD group were under physiotherapy. Furthermore, 15 patients (26.3\%) with CMD and $14(23.3 \%)$ patients with TD had a history of

\begin{tabular}{|c|c|c|c|}
\hline \multicolumn{4}{|c|}{ Table 1. Demographic characteristics of individuals in the groups under study } \\
\hline & Group & Group & $\mathbf{p}$ \\
\hline & Unilateral microscopic retractor & Tubular & \\
\hline & $\mathbf{N}=\mathbf{6 0}$ & $\mathrm{N}=61$ & \\
\hline Age $(\operatorname{mean} \pm$ SD) & $54 \pm 16.83$ & $55.89 \pm 15.56$ & 0.616 \\
\hline BMI $($ mean \pm SD $)$ & $27.59 \pm 7.53$ & $27.82 \pm 4.38$ & 0.679 \\
\hline Height (mean \pm SD) & $1.68 \pm .0 .087$ & $\mathbf{0 . 7 3} \pm \mathbf{0 . 0 9 1}$ & 0.060 \\
\hline Weight $($ mean \pm SD $)$ & $81.57 \pm 14.31$ & $83.46 \pm 14.43$ & 0.102 \\
\hline Sex Female N(\%) & $28(46.7)$ & $37(60.7)$ & 0.087 \\
\hline Osteoporosis N(\%) & $9(15)$ & $15(24.6)$ & 0.137 \\
\hline Under physiotherapy N(\%) & $31(53.4)$ & $27(44.3)$ & 0.316 \\
\hline Familiar of low back pain $\mathrm{N}(\%)$ & $15(26.3)$ & $14(23.3)$ & 0.436 \\
\hline
\end{tabular}


Discectomy and disc surgery

Eur J Transl Myol 29 (4): 320-327, 2019

Table 2. Results of discectomy based on the use of Tubulat Discectomy or Conventional Microdiscectomy

\begin{tabular}{|c|c|c|c|}
\hline & Group & Group & $\mathrm{p}$ \\
\hline & Unilateral microscopic retractor & Tubular & \\
\hline & $\mathrm{N}=60$ & $\mathrm{~N}=61$ & \\
\hline $\begin{array}{l}\text { Duration of back pain according to } \\
\text { the day }(\text { Mean } \pm \text { SD) }\end{array}$ & $32.39 \pm 61.200$ & $63.35 \pm 68.20$ & 0.148 \\
\hline Ronald Morris score $($ Mean \pm SD) & $2.98 \pm 6.033$ & $3.25 \pm 3.73$ & 0.000 \\
\hline Oswestry index (Mean \pm SD) & $12.53 \pm 7.09$ & \pm .7 .839 .51 & 0.013 \\
\hline Intensity of pain $($ Mean \pm SD) & $1.04 \pm 0.93$ & $1.67 \pm 1.33$ & 0.238 \\
\hline Personal hygiene (Mean \pm SD) & $0.93 \pm 0.75$ & $0.93 \pm 1.03$ & 0.36 \\
\hline Picking up objects (Mean \pm SD) & $2.2 \pm 1.27$ & \pm 1.231 .44 & 0.001 \\
\hline Walking (Mean \pm SD) & $1.58 \pm 1.22$ & $197 \pm 1.66$ & 0.071 \\
\hline Sit $($ Mean \pm SD) & $1.27 \pm 0.92$ & $0.704 \pm 0.84$ & 0.001 \\
\hline Stand $($ Nean \pm SD) & $1.83 \pm 1.12$ & $0.8 \pm 0.85$ & 0.000 \\
\hline Sleep $($ Mean \pm SD) & $1.08 \pm 0.99$ & $0.78 \pm 0.82$ & 0.125 \\
\hline Sex life $($ Mean \pm SD $)$ & $0.81 \pm 0.97$ & $0.66 \pm 0.78$ & 0.551 \\
\hline Social life $($ Mean \pm SD) & $0.83 \pm 0.99$ & $0.83 \pm 0.89$ & 0.794 \\
\hline Travel (Mean \pm SD) & $1.3 \pm 1.03$ & \pm 1.010 .90 & 0.024 \\
\hline VAS score $($ Mean \pm SD) & $41.03 \pm 18.61$ & $36.67 \pm 17.53$ & 0.135 \\
\hline Complications $\mathrm{N}(\%)$ & $12(20)$ & $0(0)$ & 0.000 \\
\hline
\end{tabular}

low back pain (Table 1). Furthermore, 21.7\% (13 patients) and $21.3 \%$ (13 patients) of the subjects in the unilateral retractor group and TD groups showed relapse after 6 months. The mean duration of pain was $61.200 \pm$ 32.39 days in the CMD and TD groups $63.35 \pm 63.35$ days. In the unilateral retractor group, 12 (20\%) patients were diagnosed with complications, while there was no complication in any of the patients with TD. ODI in the CMD and TD was reported to be $12.53 \pm 7.09$ and $9.51 \pm$ 7.83 , respectively. In addition, the mean score of RMQ value in the CMD group and the other group was \pm 6.033 \pm 2.98 and $3.73 \pm 3.25$, respectively, that all of the observed differences were significant $(\mathrm{p}<0.05)$. However, there was no difference between the two groups in terms of VAS score (Table 2). According to the ODI, it was also concluded that the patients with TD had less disability in lifting objects, standing, and traveling (Figure 4; $\mathrm{p}<0.05$ ). Also, we examined the role of BMI, age, sex and family history of low back pain for effectiveness of therapeutic methods. In the endoscopic interlaminar lumbar discectomy, the ODI was significantly higher in men than women $(14.37 \pm 6.21$ versus $10.43 \pm 7.19$ ). Our findings showed that the visual scores of pain were higher among those with a family history of back pain in both groups than others, so that in the CMD group, the mean score of the patients with a family history of low back pain was determined as 46.43 \pm 23.07 , while this rate was obtained to be $38.29 \pm 17.01$ in others $(\mathrm{p}=0.02)$. This rate in TD group was calculated as $50.71 \pm 10.72$ and $31.78 \pm 16.69$, respectively $(\mathrm{p}=$ $0.001)$. In the TD group, the ODI and RMQ value were also reported among patients with family history (14.92 \pm 6.29 and $5.42 \pm 2.24$ ). The ODI and RMQ value in other subjects are also $7.54 \pm 7.25$ and $3.1957 \pm 3.38$, respectively, indicating the effect of family history of subjects in their disability status $(\mathrm{p}<0.05)$ (Table 2$)$.

\section{Discussion}

Contrary to domestic studies, our research findings showed that there is a widespread background in examining the effectiveness of less invasive discectomy approaches versus classical approaches. However, few studies have investigated the patients' status after TD and classical surgery through Oswestry low back pain disability questionnaire and Roland Morris disability questionnaire. Therefore, there is no possibility of comparing the current study with other studies. In our study, TD was superior to the classical approach including conventional microdiscectomy. Rasouli et al. in the United States reported that TD causes a shorter recovery compared to the microdiscectomy/open discectomy; however, it is still not possible to definitively discuses about other differences, including back pain improvement, radicular pain, postoperative complications and recurrence within six months after surgery. ${ }^{27}$ An interventional study by Kulkari et al. 


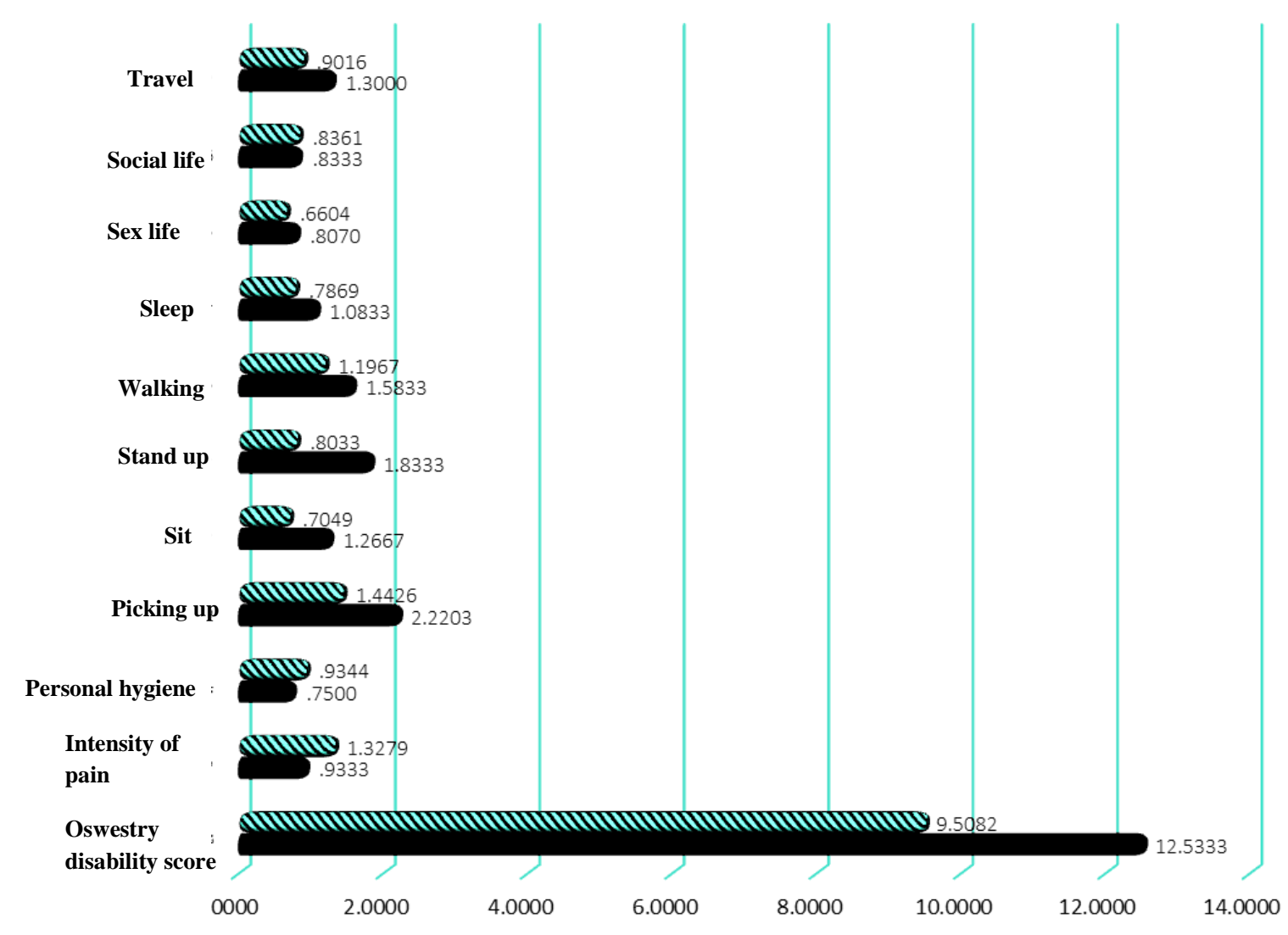

Fig 4. Oswestry disability index (ODI) in groups under study. Black color: Interlaminar. Green color: Tubular.

suggested that micro endoscopic discectomy (MED) using tubular retractors could be an effective approach for herniated discs, where its complications has been revealed in $5 \%$ of patients. ${ }^{28}$

Contrary to the current study, many studies found that there was no difference in the effectiveness of these two therapeutic approaches. A review study in the United States has shown that minimally invasive discectomy method could not be different from that of an open discectomy ${ }^{29}$. In another study by Arts et al, it has been reported that the rate of $\mathrm{CPK}$-induced muscle damage in surgery with TD was not significantly different from that of a conventional microdiscectomy. ${ }^{26}$ Muramatsu et al have also achieved similar results. ${ }^{31}$

Other studies have indicated that there was no significant difference between the TD and the classical approach in terms of pain score. ${ }^{32-33}$ Akinduro et al. have shown no significant difference between the less invasive methods of the discectomy and the classical methods regarding outcomes of approaches; however, patients with TD had a lower re-surgery rate than conventional approches. ${ }^{34}$ In our study, the rate of re-operation was not investigated. In another study, the incidence of low back pain was evaluated based on Oswestry disability index. They stated that the incidence of low back pain was observed in $15-25 \%$ of patients within 2 years old, and 0 to $13 \%$ of patients were again exposed to discectomy. ${ }^{35}$ Similar studies investigated the incidence of low back pain in patients after lumbar discectomy over a period of 6 months to 2 years, with varying rates. Different rates have been reported by previous studies including $11 \%$, $24 \%, 20 \%, 9 \%, 7 \%, 9 \%, 22 \%, 34 \%, 11 \%$, and $17 \%,{ }^{36-45}$ which is in line with our study. The efficacy and complications of tubular microdisectomy were previously compared with classical microdisectomy. Many studies have shown the efficacy of tubular methods in comparison with the classical method. As shown by Li et al. both methods have the same acceptable efficacy in the treatment of lumbar herniated disc by examining 10 sources of study including 840 patients. The duration of surgery, blood loss, complications during and after surgery, duration of hospitalization, Patients status based on VAS and ODI were achived to be the same in short and long term examinations among both groups. ${ }^{46}$ Bhatia et al. reported that both groups had a significant improvement in VAS score for leg pain, back pain, and ODI scores. They indicated that the mean time of MD surgery was 34 minutes shorter than TD. In contrast, the 
recovery rate in the TD group was faster as compared to conventional microdiscectomy. ${ }^{47}$ A study by Overdevest et al. indicated that the two groups did not differ significantly in terms of clinical outcomes. ${ }^{24}$ However, another study demonstrated that rates of complications, hospitalization, recurrence of the problem, infection, and the time of surgery were similar in both group, but the short-term and long-term efficacy of treatment in the TD group was lower than convetional microdiscectomy. Thus, the visual score of back and leg pain in subjects with TD was significantly higher than convetional microdiscectomy. ${ }^{48}$ Siu and Lin, in a descriptive study, investigated the effectiveness of a modified direct tubular approach for treatment of far lateral lumbar disc herniation. They revealed a significant reduction in the score of the mean Oswestry disability index $(32 ; 95 \% \mathrm{CI}$, 21-43), back pain scores (35 mm; 95\% CI, 21-48 mm), and visual analogue scale scores for leg pain $(38 \mathrm{~mm}$; $95 \% \mathrm{CI}, 23-54 \mathrm{~mm}) .{ }^{49} \mathrm{In}$ our study, the status of patients was not questioned before and after surgery, but the score for the ODI and the visual analogue scale score for back pain were determined as $3.73 \pm 3.25$ and $36.67 \pm 17.53$, respectively. Clark et al. evaluated TD and its complications in their review and demonstrated that there had been no significant difference between TD and convetional microdiscectomy in terms of complications, but the rate of bleeding in patients could be lower in tubular microdiscectomy as compared to convetional microdiscectomy, although they were not statistically significant. ${ }^{50}$

In order to choose the best candidate for any type of treatment, understanding the factors influencing the effectiveness of both therapeutic approaches, which are considered as sub-goals in this research, requires largescale studies. Different aspects should be taken into account in this area, such as surgical decision making and associated factors, as well as therapeutic costs. By incorporating these findings, the best decision can be made to apply the appropriate treatment for patients.

\section{List of acronyms}

BMI - Body mass index

CMD - Conventional microdiscectomy

MD - Microdiscectomy

MED - Micro endoscopic discectomy

ODI - Oswestry disability index

RMQ - Roland Morris disability questionnaires

TD - Tubular discectomy

VAS - Visual analogue scale

\section{Authors contributions}

Authors equally contributed to the manuscript.

\section{Acknowledgments}

None.

\section{Funding}

None.

\section{Conflict of Interest None}

\section{Ethical Publication Statement}

We confirm that we have read the Journal's position on issues involved in ethical publication and affirm that this report is consistent with those guidelines.

\section{Corresponding Author}

Hesam Abdolhoseinpour, Department of Neurosurgery, Bou Ali Hospital, Faculty of Medicine, Tehran Medical Sciences Branch, Islamic Azad University, Tehran, Iran. Email: drhesamabdolhoseinpour@gmail.com

E-mails of co-authors

Fatemeh Mahboub Mojaz:

Reza Akhavan Sigari:

f.mahboubmojaz@yahoo.com

reza.akhavan-sigari@med.uni-tuebingen.de

\section{References}

1. Verbeek JH ,Schaafsma F. Occupational back pain. In: Baxter PJ, Aw TC, Cockroft A, Durrington P, Harrington JM, editors. Hunter's diseases of occupations. 10th ed. Florida: CRC Press; 2010, pp 715-24.

2. Hemmati F. Prevalence of one-year back pain in Iran: a systematic review and metaanalysis. Iran Occup Health 2014; 11:1-12.

3. Biglarian A, Seifi B, Bakhshi E, et al. Low back pain prevalence and associated factors in Iranian population: findings from the national health survey. Pain Res Treat 2012;2012:653060.

4. Mohseni-Bandpei MA, Ahmad-Shirvani M, Golbabaei N, et al. Prevalence and risk factors associated with low back pain in Iranian surgeons. J Manipulative Physiol Ther 2011;34:362-70.

5. Rempel DM, Evanoff BA, Hagberg Met al. Musculoskeletal disorders. In: Rosenstock L, Cullen M, Brodkin C, Redlich C, editors. Textbook of clinical occupational and environmental medicine. 2nd Ed. New York: Saunders, Edinburgh; 2005, pp 495-48.

6. Braddom RL. Physical medicine and rehabilitation e-book. 4th ed. Philadelphia: Elsevier Health Sciences; 2010, pp 871-911.

7. Gibson JN, Waddell G. Surgical interventions for lumbar disc prolapse: Updated cochrane review. Spine (Phila Pa 1976) 2007;32:1735-47.

8. Hofstee DJ, Gijtenbeek JM, Hoogland PH, et al. Westeinde sciatica trial: Randomized controlled study of bed rest and physiotherapy for acute sciatica. J Neurosurg 2002;96(1 Suppl):45-9.

9. Vroomen PC, de Krom MC, Slofstra PD, Knottnerus JA. Conservative treatment of sciatica: a systematic review. J Spinal Disord 2000;13:463-9

10. Atlas SJ, Keller RB, Wu YA, et al. Long-term outcomes of surgical and nonsurgical management of sciatica secondary to a lumbar disc herniation: 10 
year results from the maine lumbar spine study. Spine (Phila Pa 1976) 2005;30:927-35.

11. Henriksen L, Schmidt K, Eskesen V, Jantzen E. A controlled study of microsurgical versus standard lumbar discectomy. Br J Neurosurg 1996;10:289_ 93.

12. Peul WC, van Houwelingen HC, van den Hout WB, et al. Surgery versus prolonged conservative treatment for sciatica. $\mathrm{N}$ Engl J Med 2007;356:2245-56.

13. Arts MP, Peul WC, Koes BW, Thomeer RT. Leiden-the Hague Spine Intervention Prognostic Study (SIPS) Group. Management of sciatica due to lumbar disc herniation in the Netherlands: A survey among spine surgeons. J Neurosurg Spine 2008;9:32-9.

14. Yasargil MG. Microsurgical operation for herniated disc. Adv Neurosurg 1977;4:81.

15. Caspar W. A new surgical procedure for lumbar disk herniation causing less tissue damage through a microsurgical approach. Adv Neurosurg 1977;4:74-7.

16. Brayda-Bruno M, Cinnella P. Posterior endoscopic discectomy (and other procedures) Eur Spine J 2000;9(Suppl 1):S24-9.

17. Kamper SJ, Ostelo RWJG, Rubinstein SM, et al. Minimally invasive surgery for lumbar disc herniation: a systematic review and meta-analysis. Eur Spine J 2014;23:1021-43.

18. Schizas C, Tsiridis E, Saksena J. Microendoscopic discectomy compared with standard microsurgical discectomy for treatment of uncontained or large contained disc herniations. Neurosurgery 2005;57 (4 Suppl):357-60.

19. Smith JS, Ogden AT, Shafizadeh S, Fessler RG: Clinical outcomes after microendoscopic discectomy for recurrent lumbar disc herniation. J Spinal Disord Tech 2010;23:30-34.

20. Caspar W: A new surgical procedure for lumbar disc herniation causing less tissue damage through a microsurgical approach. Adv Neurosurg 1977;4:74-80.

21. Yasargil MG: Microsurgical operations of herniated lumbar disc. Adv Neurosurg 1977;4:81-82.

22. Foley KT, Smith MM. Microendoscopic discectomy. Tech Neurosurg 1997;3:301-7.

23. Felbaum DR, Stewart JJ, Distaso C, Sandhu FA. Complication Rate in Minimally Invasive Revision Lumbar Discectomy: A Case Series and Technical Note. Clin Spine Surg 2017 Mar 6. doi: 10.1097/BSD.0000000000000513.

24. Overdevest GM, Peul WC, Brand R, et al. Tubular discectomy versus conventional microdiscectomy for the treatment of lumbar disc herniation: longterm results of a randomised controlled trial. J Neurol Neurosurg Psychiatry 2017;88:1008-16.

25. Arts M, Brand R, van der Kallen B, et al. Does minimally invasive lumbar disc surgery result in less muscle injury than conventional surgery? A randomized controlled trial. Eur Spine J 2011;20:51-7.

26. van den Akker ME, Arts MP, van den Hout WB, et al. Tubular diskectomy vs conventional microdiskectomy for the treatment of lumbar diskrelated sciatica: cost utility analysis alongside a double-blind randomized controlled trial. Neurosurgery 2011;69:829-35.

27. Rasouli MR, Rahimi-Movaghar V, Shokraneh F, et al. Minimally invasive discectomy versus microdiscectomy/open discectomy for symptomatic lumbar disc herniation. Cochrane Database Syst Rev. 2014;(9):CD010328.

28. Kulkarni AG, Bassi A, Dhruv A. Microendoscopic lumbar discectomy: Technique and results of 188 cases. Indian J Orthop 2014;48:81-7.

29. Imada AO, Huynh TR, Drazin D. Minimally Invasive Versus Open Laminectomy/Discectomy, Transforaminal Lumbar, and Posterior Lumbar Interbody Fusions: A Systematic Review. Cureus 20178;9:e1488.

30. Dasenbrock HH, Juraschek SP, Schultz LR, et al. The efficacy of minimally invasive discectomy compared with open discectomy: a meta-analysis of prospective randomized controlled trials. J Neurosurg Spine 2012;16:452-62.

31. Muramatsu K, Hachiya Y, Morita C. Postoperative magnetic resonance imaging of lumbar disc herniation: comparison of microendoscopic discectomy and Love's method. Spine 2001;26:1599-605.

32. Ostelo RW, de Vet HC. Clinically important outcomes in low back pain. Best Pract Res Clin Rheumatol 2005;19:593-607.

33. Farrar JT, Portenoy RK, Berlin JA, et al. Defining the clinically important difference in pain outcome measures. Pain 2000;88:287-94.

34. Akinduro OO, Kerezoudis P, Alvi MA, et al. Open Versus Minimally Invasive Surgery for Extraforaminal Lumbar Disk Herniation: A Systematic Review and Meta-Analysis. World Neurosurg 2017;108:924-38.

35. Parker SL, Mendenhall SK, Godil SS, et al. Incidence of Low Back Pain After Lumbar Discectomy for Herniated Disc and Its Effect on Patient-reported Outcomes. Clin Orthop Relat Res 2015;473:1988-99.

36. Carragee EJ, Spinnickie AO, Alamin TF, Paragioudakis S. A prospective controlled study of limited versus subtotal posterior discectomy: shortterm outcomes in patients with herniated lumbar intervertebral discs and large posterior anular defect. Spine (Phila Pa 1976) 2006;31:653-7.

37. Caspar W, Campbell B, Barbier DD, et al. The Caspar microsurgical discectomy and comparison with a conventional standard lumbar disc procedure. Neurosurgery 1991;28:78-86. 
38. Chatterjee S, Foy PM, Findlay GF. Report of a controlled clinical trial comparing automated percutaneous lumbar discectomy and microdiscectomy in the treatment of contained lumbar disc herniation. Spine (Phila $\mathrm{Pa}$ 1976) 1995;20:734-8.

39. Daneyemez M, Sali A, Kahraman S, et al. Outcome analyses in 1072 surgically treated lumbar disc herniations. Minim Invasive Neurosurg 1999;42:63-8.

40. Ejeskar A, Nachemson A, Herberts P, et al. Surgery versus chemonucleolysis for herniated lumbar discs. A prospective study with random assignment. Clin Orthop Relat Res 1983;174:236-42.

41. Findlay GF, Hall BI, Musa BS, et al. A 10-year follow-up of the outcome of lumbar microdiscectomy. Spine (Phila $\mathrm{Pa}$ 1976) 1998;23:1168-71.

42. Gorgulu A, Simsek O, Cobanoglu S, et al. The effect of epidural free fat graft on the outcome of lumbar disc surgery. Neurosurg Rev 2004;27:1814.

43. Kahanovitz N, Viola K, Muculloch J. Limited surgical discectomy and microdiscectomy. A clinical comparison. Spine (Phila $\mathrm{Pa}$ 1976) 1989;14:79-81.

44. Lowell TD, Errico TJ, Fehlings MG, et al. Microdiscectomy for lumbar disk herniation: a review of 100 cases. Orthopedics 1995;18:985-90.
45. MacKay MA, Fischgrund JS, Herkowitz HN, et al. The effect of interposition membrane on the outcome of lumbar laminectomy and discectomy. Spine (Phila Pa 1976) 1995;20:1793-6.

46. Li X, Chang H, Meng X. Tubular microscopes discectomy versus conventional microdiscectomy for treating lumbar disk herniation: Systematic review and meta-analysis. Medicine (Baltimore). 2018;97:e9807.

47. Bhatia PS, Chhabra HS, Mohapatra B, et al. Microdiscectomy or tubular discectomy: Is any of them a better option for management of lumbar disc prolapse. J Craniovertebr Junction Spine 2016;7:146-52.

48. Arts MP, Brand R, van den Akker ME, et al: Tubular discectomy vs conventional microdiscectomy for sciatica: a randomized controlled trial. JAMA 2009;302:149-58.

49. Siu TLT, Lin K. Direct Tubular Lumbar Microdiscectomy for Far Lateral Disc Herniation: A Modified Approach. Orthop Surg 2016;8:301-8.

50. Clark AJ, Safaee MM, Khan NR, et al. Tubular microdiscectomy: techniques, complication avoidance, and review of the literature. Neurosurg Focus 2017;43:E7.

Submission: September, 07, 2019

Acceptance: September, 09, 2019 